\title{
Impact of COVID-19 pandemic on the sleep quality of medical professionals in Brazil
}

\author{
Impacto da pandemia COVID-19 na qualidade do sono dos médicos no Brasil \\ Janaína Mariana de Araújo Miranda BRITO-MARQUES', Clélia Maria Ribeiro FRANCO 1,2,3, \\ Paulo Roberto de BRITO-MARQUES ${ }^{1,4}$, Sandra Cristina Gonçalves MARTINEZ2,3, Gilmar Fernandes do PRADO 3,5
}

\begin{abstract}
Introduction: Coronavirus pandemic began in China in 2019 (COVID-19), causing not only public health problems but also great psychological distress, especially for physicians involved in coping with the virus or those of the risk group in social isolation, and this represents a challenge for the psychological resilience in the world population. Studies showed that health professionals had psychological symptoms such as depression, anxiety, insomnia, stress, among others. Objectives: To investigate the quality of sleep and the prevalence rate of sleeping disorders among physicians during COVID-19 pandemic, and identify the psychological and social factors associated with the condition. Methods: A cross-sectional study of an online questionnaire was applied for physicians in Brazil. Among the 332 participants included, 227 were women. Sociodemographic assessment was used in the questionnaire, as well as the scale of impact on the events of modifications caused by COVID-19, assessment on sleep quality (PSQI), presence and severity of insomnia (ISI), depressive symptoms (PHQ-9), and anxiety (GAD-7). Results: Most physicians (65.6\%) had changes in sleep. Poor sleep quality was reported by $73.1 \%$, depressive symptoms were present in $75.8 \%$, and anxiety in $73.4 \%$. Conclusion: Our study found that more than $70 \%$ of the physicians assessed had impaired sleep quality, characterizing insomnia symptoms during COVID-19 outbreak. Related factors included an environment of isolation, concerns about COVID-19 outbreak and symptoms of anxiety and depression. Special interventions are needed to promote health professionals' mental well-being and implement changes in this scenario.
\end{abstract}

Keywords: COVID-19; Insomnia; Depression; Anxiety.

\section{RESUMO}

Introdução: A pandemia de coronavírus iniciada na China em 2019 (COVID-19) não só causou problemas de saúde pública mas também trouxe grande sofrimento psíquico, principalmente aos médicos envolvidos no enfrentamento da doença ou àqueles do grupo de risco em isolamento social, e representa um desafio para a resiliência psicológica da população mundial. Estudos mostram que profissionais de saúde apresentaram sintomas psicológicos como depressão, ansiedade, insônia, estresse, entre outros. Objetivos: Investigar a qualidade do sono e a taxa de prevalência de transtornos do sono entre os médicos durante a pandemia do COVID-19, e identificar os fatores psicológicos e sociais associados ao quadro. Métodos: Estudo transversal com aplicação de questionário on-line a médicos do Brasil e inclusão de 332 participantes, dos quais 227 eram mulheres. Foram utilizados questionários com avaliação sociodemográfica, escala de impacto a eventos com modificações causadas pelo COVID-19, avaliação da qualidade do sono (PSQI), presença e gravidade da insônia (IGI), sintomas depressivos (PHQ-9) e ansiedade (TAG-7). Resultados: A maioria dos médicos (65,6\%) apresentou alterações no sono, sendo a má qualidade do sono reportada por $73,1 \%$. Sintomas depressivos estiveram presentes em 75,8\%, e ansiedade em $73,4 \%$. Conclusão: Nosso estudo constatou que mais de $70 \%$ dos médicos avaliados apresentavam comprometimento da qualidade do sono, caracterizando sintomas de insônia durante o surto de COVID-19. Os fatores relacionados incluíram ambiente de isolamento, preocupações com o surto de COVID-19 e sintomas de ansiedade e depressão. Intervenções especiais são necessárias para promover o bem-estar mental dos profissionais de saúde e implementar mudanças nesse cenário.

Palavras-chave: COVID-19; Insônia; Depressão; Ansiedade.

\footnotetext{
'Universidade de Pernambuco, Hospital Universitário Oswaldo Cruz, Departamento de Neurologia, Recife PE, Brazil.

${ }^{2}$ Universidade Federal de Pernambuco, Unidade de Neurologia e Neurocirurgia, Departamento de Neuropsiquiatria, Recife PE, Brazil.

${ }^{3}$ Academia Brasileira de Neurologia, Departamento Científico de Sono, São Paulo SP, Brazil.

«Universidade de Pernambuco, Faculdade de Ciências Médicas, Recife PE, Brazil.

${ }^{5}$ Universidade Federal de São Paulo, Unidade de Neurologia, São Paulo SP, Brazil.

Janaína Mariana de Araújo Miranda BRITO-MARQUES (DD https://orcid.org/0000-0001-7886-0789;

Clélia Maria Ribeiro FRANCO (D) https://orcid.org/0000-0001-8877-2790; Paulo Roberto de BRITO-MARQUES (D) https://orcid.org/0000-0002-5977-1294; Sandra Cristina Gonçalves MARTINEZ (D) https://orcid.org/0000-0003-0977-6131; Gilmar Fernandes do PRADO (D) https://orcid.org/0000-0002-3383-8198

Correspondence: Janaina Mariana de Araújo Miranda Brito-Marques; E-mail: marianaaraujo6@gmail.com

Conflict of interest: There is no conflict of interest to declare.
}

Authors' contributions: JMAMBM: manuscript's writing, study concept and design; CMRF: manuscript's writing, study concept and design; PRBM: study concept and design; SCGM: review and design; GFP: review and design.

Received on September 23, 2020; Received in its final form October 27, 2020; Accepted on October 29, 2020. 


\section{INTRODUCTION}

Coronavirus was identified in China in the late 2019's as a responsible agent of infection called coronavirus disease 2019 (COVID-19), recognized as a worldwide pandemic by the World Health Organization (WHO) in March 2020, with a high potential of contagion and catastrophic incidence $^{1}$. Up to September 4, 2020, the virus has infected more than 26 million people, causing more than 860,000 deaths worldwide ${ }^{2}$.

Epidemiological factors related to the virus, such as its incubation period, geographic reach, number of infected people and the real mortality rate have led to insecurity and fear in the whole population in the world. The situation aggravated due to insufficient control measures and the lack of effective therapeutic approaches, in addition to the precarious public health infrastructure ${ }^{1,3}$. These uncertainties have had consequences in several sectors in the routine of people's life, with direct implications on individuals' mental health especially among health professionals as they had to deal with the extremely adverse context of this new disease ${ }^{3}$.

This high psychological burden has already been reported by health professionals in Wuhan, where the virus began, and in other regions in China 4 .

In view of the critical situation, health calamity, the health professionals, especially those who were directly involved with patients with COVID-19 in the diagnosis, treatment and care, were exposed to a greater risk of developing psychological distress and other symptoms, such as impaired mental health ${ }^{5}$. As an example, a multinational and multicenter study found a significant association between adverse psychological results and physical symptoms in health professionals during the current pandemic. Of the 906 participating health professionals, all had moderate to severe levels of suffering: $5.3 \%$ of depression, $8.7 \%$ of anxiety, $2.2 \%$ of stress, and $3.8 \%$ of adverse psychological suffering ${ }^{6}$.

There are data showing that health professionals involved in coping with the outbreak of COVID-19 are more likely to have poor sleep quality compared to other occupational groups ${ }^{7}$. The experience of this whole set of difficulties, as mentioned above, as well as the alarming information that generate fear and insecurity, can trigger difficulties in starting and continuing to sleep, resulting in a sensation of non-restorative sleep, characteristic symptoms of insomnia. Insomnia has a direct and increased association in this context of psychological distress, impairing the quality of sleep, becoming a negative incremental factor on individuals' physical and psychological health who are experiencing the pandemic ${ }^{8,9}$.

This study is justified by the need to understand the impact of this enormous change promoted by the pandemic on the physicians' sleep patterns who are involved and coping with COVID-19, allowing preventive or therapeutic measures to be taken on these professionals, particularly those exposed to the effects of unusual working conditions, restrictions and insecurity. It is also justified by the fact that after the pandemic many of the insomnia conditions may persist, reinforcing unhealthy habits in relation to sleep, perpetuating an adverse state to physical and mental health.

\section{METHODS}

\section{Study design}

Cross-sectional study involving 332 physicians participating or not on the frontline of suspected or confirmed cases of COVID-19 in Brazil. An online form was used from the Google Forms platform; by means of a link shared through social media, WhatsApp, e-mail or other online systems, physicians working in different health services (primary care services, urgencies and emergencies, tertiary services, medical residency groups, public or private hospitals) were invited to perform the assessment regardless of specialties and Brazilian socio-demographic situation.

\section{Measuring instruments}

Through the online questionnaire, we collected sociodemographic data and administer scales to assess sleep quality, presence and severity of insomnia, as well as the symptoms of depression and anxiety. The sociodemographic characterization was carried out through a structured questionnaire gathering information about age group, sex, ethnicity, residential location, household members (family, spouse, friends, alone, others), if they had children, if they were attending medical residency and year, area of activity, presence of comorbidities (with specification), if they were in contact with COVID-19 in their work sector, if they were removed, relocated or belonged to any risk group.

In this study, we used two instruments considered essential to assess sleep according to the American Academy of Sleep Medicine:

- Insomnia Severity Index (ISI) ${ }^{10}$ - it has been used to screen insomniacs and to evaluate the effectiveness of treatments used in clinical and population studies, as it has excellent psychometric properties and the ability to differentiate individuals with and without insomnia. Each item is rated on a scale of 0 to 4 points, and the total score ranges from 0 to 28 . A total score $\geq 8$ is compatible with diagnosis of insomnia, referring to mild ( 8 to 14 points), moderate (15 to 21 points) and severe (22 to 28 points).

- Pittsburgh Sleep Quality Index (PSQI) - translated and validated into Brazilian Portuguese by Bertolazi et al. ${ }^{11}$, consists of 19 questions regarding sleep quality in the last month. The questionnaire assesses 7 components of sleep: subjective quality, latency, duration, effectiveness, disorders, medication use, and daily dysfunction. For each component, the score can vary from 0 to 3 , with 
a maximum score of 21 points. Scores above 5 indicate poor sleep quality.

To assess anxiety and depressive symptoms, we used Patient Health Questionnaire-9 (PHQ-9) and Generalized Anxiety Disorder (GAD-7):

- PHQ-912 - consists of 9 items used to measure symptoms of anxiety, depression, and each of the 9 items scores on a scale of 0 to 3 . The total score suggests different levels of depression: minimal/no depression (0-4), mild (5-9), moderate (10-14) or severe (15-21).

- $\mathrm{GAD}$ scale $\mathrm{e}^{13}$ - it is a simple instrument containing 7 items that is based on the Diagnostic and Statistical Manual of Mental Disorders-fourth edition (DSM-IV) criteria and can easily track anxiety symptoms. The total score can be categorized into 4 groups of severity: minimal/no anxiety (0-4), mild (5-9), moderate (10-14) or severe (15-21).

We assessed the pandemicimpact with the Impact of Event Scale with modifications for COVID-19 (IES-COVID19) ${ }^{14}$. It shows to be valid and presented reliable measures that can be used to investigate stressed symptoms related to trauma associated with a short- and long-term impact. The instructions have been adapted to apply specifically in relation to COVID-19. We also addressed in this evaluation the presence of symptoms related to the pandemic, such as fear of being contaminated and transmitting the disease; safety in the workplace; use or increased use of tobacco, alcohol, marijuana and stimulating substances (amphetamine and cocaine); search for pandemic-related news; or perceived impairment of social relationships.

\section{Data processing and analysis}

The data collected from the physicians using the Google Forms were exported to the Statistical Package for the Social Sciences (SPSS) in 13.0 version, constituting the database for statistical analysis in line with the objectives of this study.

In order to characterize the researched sample, we performed a descriptive analysis of the data. We calculated the absolute $(\mathrm{N})$ and relative (\%) frequencies with the categorical/qualitative variables of interest, as well as graphs; in the case of quantitative variables, descriptive measures were obtained, such as minimum, median, mean, standard deviation (SD) and maximum. We performed the chi-square test to verify a statistically significant association between sleep quality and the presence of depression and anxiety. We considered variables with $\mathrm{p}<5 \%$ as being significant.

\section{Ethical considerations}

Anonymity and confidentiality of data were ensured. The research project was carried out in accordance with the provision of the Resolution 466/12, reviewed and subordinated to the National Health Council for conducting research on Human Beings, and approved by the Research
Ethics Committee. The agreement of the Informed Consent Form (ICF) was a mandatory item to continue the participation and contained the necessary information to clarify the research proposal, as well as voluntary participation, risks, benefits and data related to the Research Committee.

\section{RESULTS}

\section{Sociodemographic characterization}

The study was carried out with the participation of 332 physicians distributed in 18 Brazilian states. Most were female $(67.8 \%)$, average age was 36 years, age group distribution was between 18-25 (6.9\%), 26-30 (33.7\%), 31-35 (18.7\%), $36-40$ (13.3\%), 41-60 (25.3\%) and more than 60 years $(2.1 \%)$.

Of the participants, $60.2 \%$ were considered white, $32.8 \%$ were mixed and $5.4 \%$ were black. They had some comorbidity (47.4\%), being the psychiatric - including depression, generalized anxiety disorder, panic disorder, bipolar disorder, among others - more prevalent (13.3\%), and obesity (6.3\%). The physicians were divided into 27 specialties: surgical specialties (10.5\%), general practitioners (9.3\%), family and community medicine $(10.8 \%)$, emergency/intensive care $(8.7 \%)$, Pediatrics (13.6\%), Neurology (14.5\%) and other clinical specialties $(5.1 \%)$. Of the responses obtained, $28 \%$ were physicians who were attending the medical residency program. Approximately $88 \%$ of the physicians worked in a sector with the possibility of contacting patients with COVID-19. Of these, $31 \%$ had their function modified to meet the demand to care for patients with COVID-19 and 3\% were removed from their duties because they belonged to a risk group.

On the IES-COVID19, 64.1\% had fear of having or transmitting the disease, and $61 \%$ felt unsafe at the work environment. Regarding to the consumption of alcohol and tobacco, $36.2 \%$ showed an increase in the consumption of alcoholic beverages, and $4 \%$ started to use or increased their tobacco habit. There was a $4.2 \%$ of increase in the consumption of stimulants, such as cocaine or amphetamines.

\section{Assessment on the aspects of mental health, depression, anxiety and sleep-related symptoms}

The prevalence of depression, anxiety and poor sleep quality symptoms was $73.1 \%$ (PHQ-9 $\geq 5$ ), 75.8\% (GAD-7 $\geq 5$ ) and $73.4 \%$ (Pittsburgh $\geq 5$ ), respectively. Table 1 shows a significant relationship ( $\mathrm{p}<0.001)$ among the symptoms of anxiety $(85.5 \%)$, depression (85.6\%) and insomnia (80.8\%) with poor sleep quality (Pittsburgh $>5$ ).

According to the data in Table 2, the study revealed that most physicians $(65.6 \%)$ had complaints in relation to sleep, with symptoms compatible with mild (37.2\%), moderate $(23.3 \%)$ and severe insomnia $(5.1 \%)$, according to the ISI. Among the main aspects questioned, $74 \%$ reported difficulty in initiating sleep, $66.5 \%$ had problems with early awakening, and $66.2 \%$ difficulty in continuing to sleep (Figure 1). 
Table 1. Correlation between sleep quality (Pittsburgh questionnaire) and the variables Insomnia Severity Index, Generalized Anxiety Disorder Scale and depression symptoms.

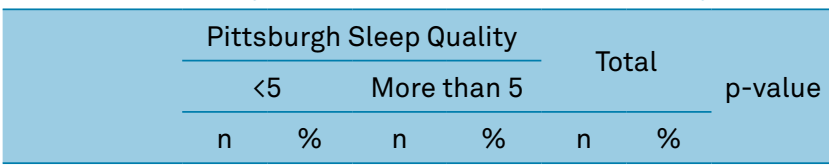

Insomnia Severity Index

$\begin{array}{lcccccccc}\begin{array}{l}\text { Normal } \\ (0 \text { to } 7)\end{array} & 65 & 86.7 & 49 & 19.1 & 114 & 34.4 & \\ \begin{array}{l}\text { Mild } \\ (8 \text { to 14) }\end{array} & 10 & 13.3 & 113 & 44.1 & 123 & 37.2 & \\ \begin{array}{l}\text { Moderate } \\ (15 \text { to } 21)\end{array} & 0 & 0.0 & 77 & 30.2 & 77 & 23.3 & \\ \begin{array}{l}\text { Severe } \\ (22 \text { to } 28)\end{array} & 0 & 0.0 & 17 & 6.6 & 17 & 5.1 & <0.001\end{array}$

Generalized Anxiety Disorder Scale

$\begin{array}{lccccccc}0 \text { to } 4 & 43 & 57.3 & 37 & 14.5 & 80 & 24.2 & \\ 5 \text { to } 9 & 27 & 36.0 & 92 & 35.9 & 119 & 36.0 & \\ 10 \text { to } 14 & 4 & 5.3 & 60 & 23.4 & 64 & 19.3 & \\ \geq 15 & 1 & 1.3 & 67 & 26.2 & 68 & 20.5 & <0.001\end{array}$

Depression symptoms

\begin{tabular}{lccccccc}
0 to 4 & 52 & 69.3 & 37 & 14.4 & 89 & 26.9 & \\
5 to 9 & 19 & 25.3 & 75 & 29.3 & 94 & 28.4 & \\
10 to 14 & 4 & 5.3 & 69 & 27.0 & 73 & 22.1 & \\
15 to 19 & 0 & 0.0 & 45 & 17.6 & 45 & 13.6 & \\
20 to 27 & 0 & 0.0 & 30 & 11.7 & 7 & 9.1 & $<0.001$ \\
\hline
\end{tabular}

Table 2. Insomnia Severity Index among doctors assessed during the COVID-19 pandemic period ( $n=332$ [65.6\% \pm 6.51 SD]).

\begin{tabular}{lcc}
\hline Insomnia Severity Index & $\mathrm{n}$ & $\%$ \\
\hline Normal (0 to 7) & 114 & 34.4 \\
Mild (8 to 14) & 123 & 37.2 \\
Moderate (15 to 21) & 77 & 23.3 \\
Severe (22 to 28) & 17 & 5.1 \\
\hline
\end{tabular}

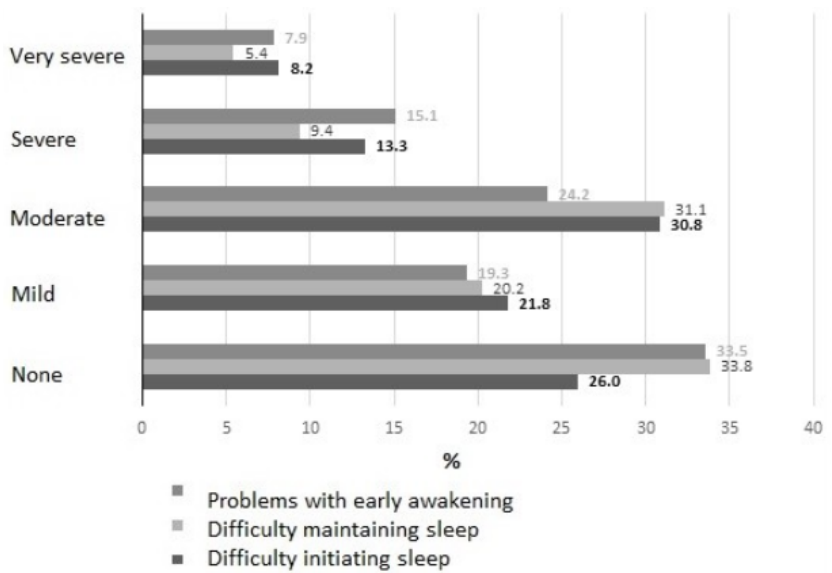

Figure 1. Assessment of the severity of insomnia related to the problems of sleep onset, maintenance and early awakening.
In addition, $61 \%$ had some degree of dissatisfaction with the current sleep pattern, $49.2 \%$ believed that their problem with sleep was noticeable to other people, and $75.8 \%$ believed that their problem of sleep interfered with their daytime activities due to daytime fatigue, some degree of impairment in their ability to work/perform daily activities, concentration, memory, mood (Figures 2, 3 and 4, respectively). The physicians' average sleep time score was 6 hours within 24 hours $( \pm 1.3 \mathrm{SD})$, with an average latency time to sleep onset in 46.8 minutes $( \pm 47.8 \mathrm{SD})$ and 7.5 hours $( \pm 1.6 \mathrm{SD})$ of staying in bed at night (not necessarily sleeping).

In the subgroup of resident physicians (28\%), $65.6 \%$ had symptoms of insomnia according to the ISI - exactly the same percentage obtained from the analysis of the total sample of participants, and $26.9 \%$ reached scores classified as moderate to severe insomnia (Table 3 ).

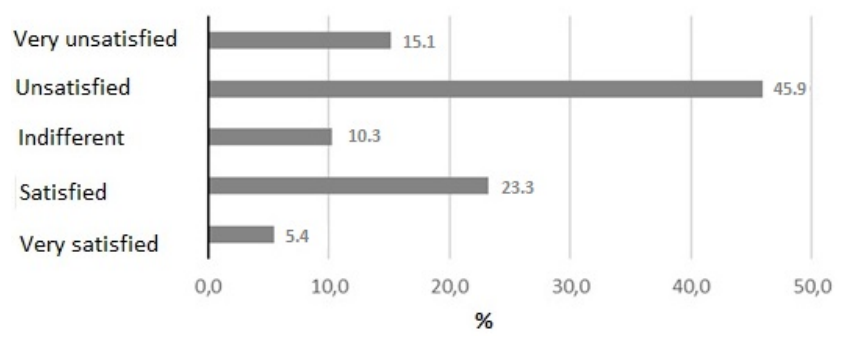

Figure 2. Assessment of the degree of satisfaction with the sleep pattern — Insomnia Severity Index.

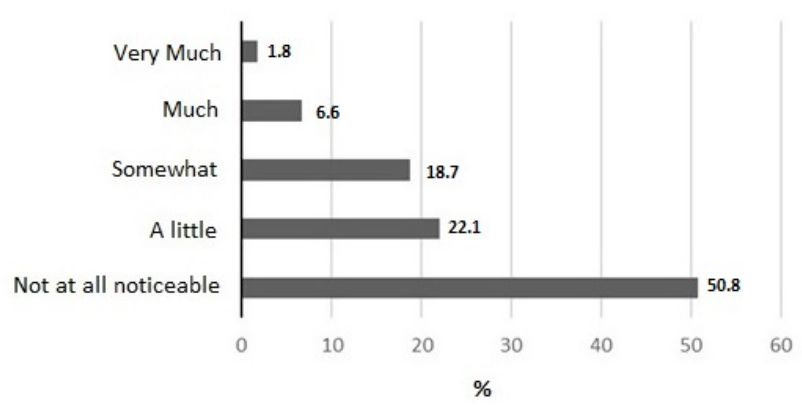

Figure 3. Other people's perception of their sleep patterns and quality of life - Insomnia Severity Index.

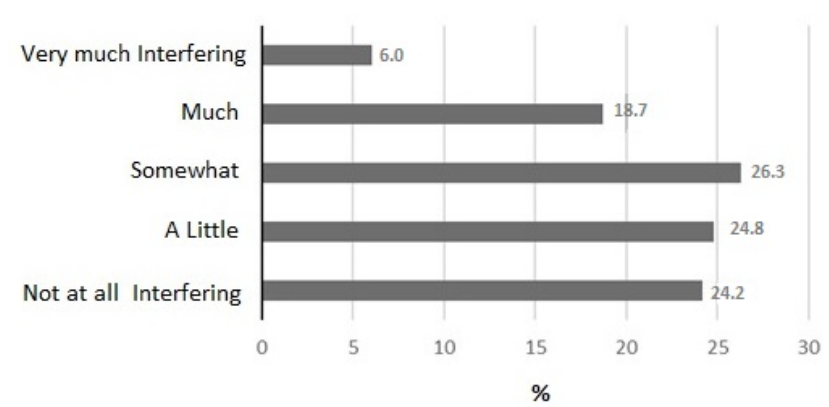

Figure 4. Impact of sleep patterns on daytime activities Insomnia Severity Index. 
Table 3. Evaluation of the Insomnia Severity Index in the subgroup of resident physicians assessed during the COVID-19 pandemic period ( $n=93$ [28\%]).

\begin{tabular}{lcc}
\hline $\begin{array}{l}\text { Insomnia Severity Index } \\
\text { (Resident physicians) }\end{array}$ & $\mathrm{n}$ & $\%$ \\
\hline Normal (0 to 7) & 32 & 34.4 \\
Mild (8 to 14) & 36 & 38.7 \\
Moderate (15 to 21) & 20 & 21.5 \\
Severe (22 to 28) & 5 & 5.4 \\
\hline
\end{tabular}

\section{DISCUSSION}

It is known that the main contributors to the emergence or potential worsening of a situation of poor sleep quality are the increased levels of stress and sudden changes in the sleep routine ${ }^{15}$. Several factors are possibly associated with physical and mental stress to which health professionals are exposed in pandemic situations such as COVID-19: the medical team often needs to have personal protective equipment (PPE) for 12 hours or more on duty, including doublelayer protective equipment, masks, gloves, cloaks, caps and goggles ${ }^{16}$. In addition to the feeling of insecurity at the work environment, as well as increased consumption of stimulating substances, alcohol and/or tobacco were pointed out in our study as contributing factors to the symptoms of anxiety, depression and poor sleep quality, with consequent repercussions on insomnia severity.

Our data, as well as those in the literature, show that these professionals usually experience stress in the context of pandemics, namely: increased risk of being infected, getting ill and dying; possibility of inadvertently infecting others; overload and fatigue; frustration for not being able to save lives, despite efforts; threats and aggression, perpetrated by people who seek care and cannot be accepted due to limited resources; and separation from family and friends ${ }^{17}$. Regarding to COVID-19 in particular, the challenges faced by physicians can trigger or intensify symptoms of anxiety, depression and stress, especially when it comes to those working on the so-called "front line"18. In this study, a significant proportion of participants experienced the symptoms of anxiety (75.8\%), depression $(73.1 \%)$ and poor sleep quality $(73.4 \%)$. In general, these professionals have been discouraged to interact closely with other people, which tends to increase the feeling of isolation; and, still, they usually dedicate significant time of their day to put on and remove personal protective equipment, which increases the exhaustion related to work ${ }^{19,20}$. Faced with these conditions, the medical team is mentally and physically exhausted, and therefore has an increased risk of insomnia due to the high level of stress during the day.

In addition, sleeping disorders can have direct consequences on the emotional functioning on the next day. Work overload and symptoms related to stress make health professionals very vulnerable to psychological distress, which increases the chance of developing psychiatric disorders and insomnia symptoms ${ }^{21}$, as it had occurred with some of the health professionals who participated in this study during the pandemic.

We found that almost half $(47.4 \%)$ of the physicians reported some previous comorbidity. Among those mentioned, psychiatric (13.3\%) were the most mentioned, highlighting depression, generalized anxiety disorder, panic disorder and bipolar disorder. We consider these symptoms relevant, as psychiatric conditions are known to be an important contributing factor for sleep impairment and insomnia in relation to healthy ones ${ }^{21}$; and more than $25 \%$ of the psychiatric patients have the same symptoms as those of post-traumatic stress and moderate to severe insomnia ${ }^{22}$. Interventions with an emphasis on mental health, including the work of psychologists and psychiatrists can contribute to the strengthening of the support network, by encouraging them to maintain frequent contacts, during breaks at work, through phone calls, text messages, audio and video $^{23,24}$. This also tends to benefit the mental health of people in the support network of health professionals, as keeping them informed may reduce negative emotions, such as fear and anguish ${ }^{24}$. Insomnia is the main complaint of sleep in terms of incidence and recurrence in the day-to-day of the most varied health professionals and has a major negative impact on the quality of life of these individuals, especially when it becomes chronic, increasing morbidity and mortality, performance in personal, work and social life, generating high direct and indirect $\operatorname{costs}^{25,26}$. Despite its great clinical relevance, insomnia is not diagnosed and evaluated in a systematic way, a fact well illustrated by the great variability in its prevalence reported in the literature ${ }^{27,28}$. Insomnia and chronic sleep deprivation represent an independent risk factor for psychiatric disorders such as ideation, attempts and suicidal death ${ }^{25}$. Therefore, in our assessment, physicians not only had particularly high scores on the symptoms of depression, anxiety and insomnia, but we also found a repercussion of these symptoms on poor sleep quality and mental health, which requires special care.

It is essential that the psychological support and intervention measures involved in the context of a crisis also aim to offer in coping with strategies to deal with intrusive thoughts and anticipatory or situational anxiety ${ }^{29}$. It is important to highlight the complexity of the Brazilian health system, in which the health professionals who work in different levels of complexity may need different strategies on information, support or interventions. Moreover, historically, few mental health programs are available for health professionals ${ }^{30}$. There are few studies in Brazil that address epidemiological data and intervention models focused on health professionals' mental health who were involved in assisting patients with COVID-19. Understanding the problems encountered in the 
insomnia group can help Health Service managers with effective education and training for mental health care. The present study aimed to draw attention to the relevance of the topic and suggests the implementation of both research and health care, especially for those with different psychosocial risk factors.

The possible limitations of this study are that some medical specialties were not included, and the scope to include frontline doctors or not was limited to the scope of sharing the questionnaire through social network, but participation in the study was completely voluntary, with an acceptable response rate. Another limitation of the Brazilian study was that it did not reach the 26 States of the federation.
This study revealed that most physicians experienced sleep-related problems during the COVID-19 outbreak. Sleep duration was considered insufficient and the quality unsatisfactory, in addition to the decreased physical and mental functioning during the day. We observed high rates on the symptoms of insomnia, anxiety and depression, contributing significantly to poor sleep quality. Adequate treatment for sleep disorders is always vital, contributing to physical and mental health, reducing vulnerability to worsen or onset psychiatric disorders and risk of suicide. Special interventions in promoting health professionals' mental wellbeing need to be implemented to change this scenario.

\section{References}

1. Boletim Epidemiológico 8. COE Coronavírus - Secretaria de Vigilância em Saúde. Ministério da Saúde 09 de abril de 2020. Semana Epidemiológica 15. Available from: https://www.saude.gov.br/ images/pdf/2020/April/09/be-covid-08-final-2.pdf

2. World Health Organization. Coronavirus disease (COVID-2019) situation reports. Available from: https://www.who.int/emergencies/ diseases/novel-coronavirus-2019/situation-reports

3. Ornell F, Schuch JB, Sordi AO, Kessler FHP. "Pandemic fear" and COVID-19: mental health burden and strategies. Braz J Psychiatry. 2020 May-Jun;42(3):232-5. https://doi.org/10.1590/1516-4446-2020-0008

4. Lai J, Ma S, Wang Y, Cai Z, Hu J, Wei N, et al. Factors associated with mental health outcomes among health care workers exposed to coronavirus disease 2019. JAMA Netw Open. 2020 Mar;3(3):e203976. https://doi.org/10.1001/jamanetworkopen.2020.3976

5. Kang L, Li Y, Hu S, Chen M, Yang C, Yang BX, et al. The mental health of medical workers in Wuhan, China dealing with the 2019 novel coronavirus. Lancet Psychiatry. 2020 Mar;7(3):e14. https://doi. org/10.1016/S2215-0366(20)30047-X

6. Chew NWS, Lee GKH, Tan BYQ, Jing M, Goh Y, Ngiam NJH, et al. A multinational, multicentre study on the psychological outcomes and associated physical symptoms amongst healthcare workers during COVID-19 outbreak. Brain Behav Immun. 2020 Aug;88:559-65. https://doi.org/10.1016/j.bbi.2020.04.049

7. Huang $Y, Z$ hao N. Generalized anxiety disorder, depressive symptoms and sleep quality during COVID-19 outbreak in China: a web-based cross-sectional survey. Psychiatry Res. 2020 Jun;288:112954. https://doi.org/10.1016/j.psychres.2020.112954

8. Azzez SS, Abdulah DM, Piro RS, Alhakem SSM. Sleep severity and fatigue manifestations in relation to the doctor-patient relationship. Sleep Med. 2019 Jun;58:13-17.https://doi.org/10.1016/j.sleep.2019.02.015

9. Abdulah M D, Musa D H. Insomnia and stress of physicians during COVID-19 outbreak. Sleep Medicine X. 2020;2:100017. https://doi. org/10.1016/j.sleepx.2020.100017

10. Castro LS. Adaptação e validação do Índice de Gravidade de Insônia (IGI): caracterização populacional, valores normativos e aspectos associados. 2011. 104f. Dissertação (Mestrado em Ciências) Universidade Federal de São Paulo, São Paulo; 2011.

11. Bertolazi AN, Fagondes SC, Hoff LS, Dartora EG, Miozzo IC, de Barba $\mathrm{ME}$, et al. Validation of the Brazilian Portuguese version of the Pittsburgh Sleep Quality Index. Sleep Med. 2011 Jan;12(1):70-5. https://doi.org/10.1016/j.sleep.2010.04.020

12. Moreno AL, Sousa DA de, Souza AMFLP, Manfro GG, Salum GA, Koller $\mathrm{SH}$, et al. Factor structure, reliability, and item parameters of the Brazilian-Portuguese version of the GAD-7 questionnaire. Temas Psicol. 2016;24(1):367-76. https://dx.doi.org/10.9788/tp2016.1-25
13. Kroenke K, Spitzer RL, Williams JBW. The PHQ-9: validity of a brief depression severity measure. J Gen Intern Med. 2001 Sep;16(9):60613. https://doi.org/10.1046/j.1525-1497.2001.016009606.x

14. Vanaken L, Scheveneels S, Belmans E, Hermans D. Validation of the impact of event scale with modifications for COVID-19 (IESCOVID19). Front Psychiatry. 2020;11:738. https://doi.org/10.3389/ fpsyt. 2020.00738

15. Orsini M, Nascimento JSF, Azizi M, Cardoso CE, Castro R, Nunes NSM, et al. Insomnia During the COVID-19 Outbreak in Brazil. Rev Saúde. 2020 Jan-Jun;11(1):84-6. https://doi.org/10.21727/ rs.v11i1.2336

16. Xiang YT, Yang Y, Li W, Zhang L, Zhang Q, Cheung T, et al. Timely mental health care for the 2019 novel coronavirus outbreak is urgently needed. Lancet Psychiatry. 2020 Mar;7(3):228-9. https://doi. org/10.1016/S2215-0366(20)30046-8

17. Santos CF. Reflections about the impact of the SARS-COV-2/ COVID-19 pandemic on mental health. Braz J Psychiatry. 2020;42(3):329. https://doi.org/10.1590/1516-4446-2020-0981

18. Schmidt B, Crepaldi MA, Bolze SDA, Neiva-Silva L, Demenech LM. Saúde mental e intervenções psicológicas diante da pandemia do novo coronavírus (COVID-19). Estud Psicol (Campinas). 2020 May;37:e200063. https://dx.doi.org/10.1590/1982-0 $275202037 \mathrm{e} 200063$

19. Bao Y, Sun Y, Meng S, Shi J, Lu L. 2019-nCoV epidemic: address mental health care to empower society. Lancet. 2020 Feb;395(10224):e37-e38. https://doi.org/10.1016/S0140-6736(20)30309-3.

20. Li Z, Ge J, Yang M, Feng J, Qiao M, Jiang R, Bi J, et al. Vicarious traumatization in the general public, members, and non-members of medical teams aiding in COVID-19 control. Brain Behav Immun. 2020 Aug;88:916-9. https://doi.org/10.1016/j.bbi.2020.03.007

21. Zhang C, Yang L, Liu S, Ma S, Wang Y, Cai Z, et al. Survey of insomnia and related social psychological factors among medical staff involved with the 2019 novel coronavirus disease outbreak. Front Psychiatry. 2020 Apr;11:306. https://doi.org/10.3389/ fpsyt.2020.00306

22. Hao F, Tan W, Jiang L, Zhang L, Zhao X, Zou Y, et al. Do psychiatric patients experience more psychiatric symptoms during COVID-19 pandemic and lockdown? A case-control study with service and research implications for immunopsychiatry. Brain Behav Immun. 2020 Jul;87:100-6. https://doi.org/10.1016/j.bbi.2020.04.069

23. Morin C, Schaefer K, Roach J, Pfleeger K, McCall W, Roth T. Baseline sleep impairment as assessed by the insomnia severity index in patients with primary insomnia and insomnia co-morbid with psychiatric or other physical disorders. Sleep. 2007; (Abstract Supplement 0721)30:A245. 
24. Ornell F, Halpern SC, Kessler FHP, Narvaez JCM. The impact of the COVID-19 pandemic on the mental health of healthcare professionals Cad Saúde Pública. 2020 Apr;36(4):e00063520. https://doi.org/10.1590/0102-311×00063520

25. Sher L. COVID-19, anxiety, sleep disturbances and suicide. Sleep Med. 2020 Jun;70:124. https://doi.org/10.1016/j.sleep.2020.04.019

26. Rosekind MR, Gregory KB. Insomnia risks and costs: health, safety, and quality of life. Am J Manag Care. 2010 Aug;16(8):617-26.

27. Banerjee D. The COVID-19 outbreak: crucial role the psychiatrists can play. Asian J Psychiatr. 2020 Apr;50:102014. https://doi. org/10.1016/j.ajp.2020.102014
28. Brooks SK, Webster RK, Smith LE, Woodland L, Wessely S, Greenberg $\mathrm{N}$, et al. The psychological impact of quarantine and how to reduce it: rapid review of the evidence. Lancet. 2020 Mar;395(10227):912-20. https://doi.org/10.1016/S0140-6736(20)30460-8

29. Sivertsen B, Krokstad S, Overland S, Mykletun A. The epidemiology of insomnia: associations with physical and mental health. The HUNT-2 study.J Psychosom Res. 2009 Aug;67(2):109-16. https://doi. org/10.1016/j.jpsychores.2009.05.001

30. Taylor DJ, Lichstein KL, Durrence HH, Reidel BW, Bush AJ.

Epidemiology of insomnia, depression, and anxiety. Sleep. 2005 Nov;28(11):1457-64. https://doi.org/10.1093/sleep/28.11.1457 